\title{
Self-reported price of cigarettes, consumption and compensatory behaviours in a cohort of Mexican smokers before and after a cigarette tax increase
}

\author{
Belen Saenz-de-Miera, ${ }^{1}$ James F Thrasher, ${ }^{1,2}$ Frank J Chaloupka, ${ }^{3}$ Hugh R Waters, ${ }^{4}$ \\ Mauricio Hernandez-Avila, ${ }^{5}$ Geoffrey T Fong ${ }^{6,7}$
}

- Additional materials are published online only. To view these files please visit the journal online

(http://tobaccocontrol.bmj.com).

${ }^{1}$ Tobacco Research Department, Center for Population Health Research, National Institute of Public Health, Cuernavaca,

Morelos, Mexico

${ }^{2}$ Department of Health

Promotion, Education and Behaviour, Arnold School of Public Health, University of South Carolina, Columbia, South Carolina, USA

${ }^{3}$ Department of Economics and Institute for Health Research and Policy, University of Illinois at Chicago, Chicago, Illinois, USA

${ }^{4}$ Department of Health Policy and Management, Johns Hopkins Bloomberg School of Public Health, Johns Hopkins University, Baltimore Maryland, USA

${ }^{5}$ Undersecretary for Health Promotion and Disease Prevention, Ministry of Health, Mexico City, Mexico

${ }^{6}$ Department of Psychology, University of Waterloo, Waterloo, Ontario, Canada ${ }^{7}$ Ontario Institute for Cancer Research, Toronto, Ontario, Canada

\section{Correspondence to} James F Thrasher, Department of Health Promotion, Education and Behaviour, 800 Sumter Street, Room 215, Arnold School of Public Health, University of South Carolina Columbia, SC 29208, USA; thrasher@mailbox.sc.edu

Received 12 June 2009 Revised 24 May 2010 Accepted 2 June 2010 Published Online First 24 September 2010

\section{UN1OCKED}

This paper is freely available online under the BMJ Journals unlocked scheme, see http:// tobaccocontrol.bmi.com/site/ about/unlocked.xhtml

\section{ABSTRACT}

Objective To assess the impact of a 2007 cigarette tax increase from $110 \%$ to $140 \%$ of the price to the retailer on cigarette price and consumption among Mexican smokers, including efforts to offset price increases.

Methods Data were analysed from the 2006 and 2007 administrations of the International Tobacco Control (ITC) Policy Evaluation Survey in Mexico, which is a population-based cohort of adult smokers. Selfreported price of last cigarette purchase, place of last purchase, preferred brand, daily consumption and quit behaviour were assessed at baseline and follow-up. Results Self-reported cigarette prices increased by $12.7 \%$ after the tax increase, with prices for international brands increasing more than for national brands $(13.5 \%$ vs $8.7 \%$, respectively). Although the tax increases were not fully passed onto consumers particularly on national brands, no evidence was found for smokers changing behaviour to offset price increases. Consistent declines in consumption across groups defined by sociodemographic and smoking-related psychosocial variables suggest a relatively uniform impact of the tax increase across subpopulations. However, decreased consumption appeared limited to people who smoked relatively more cigarettes a day (>5 cigarettes/day). Average daily consumption among lighter smokers did not significantly decline. A total of $13 \%(n=98)$ of the sample reported being quit for a month or more at follow-up. In multivariate models, lighter smokers were more likely than heavier smokers to be quit.

Conclusions Results suggest that the 2007 tax increase was passed on to consumers, whose consumption generally declined. Since no other tobacco control policies or programmes were implemented during the period analysed, the tax increase appears likely to have decreased consumption.

\section{INTRODUCTION}

A large tax increase on tobacco is the single most effective tobacco control policy. ${ }^{1}$ Tax increases generally translate into price increases for the consumer, and higher prices are associated with lower levels of consumption, reduced prevalence, increased cessation and reduced initiation. ${ }^{2} 3$ Price elasticity for tobacco demand has been estimated at -0.4 and -0.8 for developed and developing countries, respectively. ${ }^{4}$ In other words, a $10 \%$ increase in tobacco prices reduces overall consumption by approximately $4 \%$ in developed countries and by approximately $8 \%$ in developing countries. For Mexico, which is an upper middle-income country, Sesma et al ${ }^{5}$ estimated price elasticity at -0.62; however, this estimate involved analysing prices that were confounded by other factors and excluded households that should have been included in the analysis. After addressing these shortcomings, Jimenez et al ${ }^{7}$ estimated price elasticity at -0.52 , suggesting that a $10 \%$ price increase should decrease consumption by $5.2 \%$.

Previous studies of cigarette taxes in Mexico have used aggregate or household-level consumption data and, as such, cannot assess the impact of taxes on individual perceptions and behaviour. Studies using individual-level data have been conducted primarily in high-income countries, where results indicate that higher cigarette taxes and prices prevent youth from starting to smoke and lead current smokers to reduce consumption or quit. ${ }^{8}$ However, the tobacco industry may use compensating pricing strategies, such as the development of lower price branded generics and the introduction of multipack discounts to offset increases in taxes. ${ }^{9}$ Furthermore, some smokers offset increases in taxes by making special efforts to buy cheaper cigarettes. $^{10-12}$

In Mexico, cigarettes are subject to two ad valorem taxes: the special production and services $\operatorname{tax}$ (SPST) and value added tax (VAT), both set by the federal government. At the end of 2006, gradual increments to the SPST were approved. At the beginning of 2007, the SPST was increased from $110 \%$ of the price to the retailer to $140 \%$, with subsequent annual increases to $150 \%$ in 2008 and $160 \%$ in 2009 . The VAT remained at $15 \%$ of the price to the consumer in those years. The taxable base for the SPST (ie, the price to the retailer) includes the factory price and the wholesaler's profit and overhead. The taxable base for the VAT includes the price to the retailer, the SPST, and the retailer's profit and overhead, estimated on average at $10.7 \%$ of the price to the retailer after SPST. Expressed as a percentage of the final price, the joint incidence of the SPST and the VAT was $54.2 \%$ in 2006 and $58.9 \%$ in 2007 . Because of the addictive nature of cigarettes and the oligopolistic structure of the cigarette industry, an increase in taxes is expected to increase final prices at least in the same proportion. $^{2}$ As such, a tax increase from $110 \%$ of the price to the retailer to $140 \%$ would be expected to increase the final price by $14.3 \% .^{13}$

This study assesses the potential impact of this cigarette tax increase by examining the following data in a cohort of adults Mexican smokers before and after the tax increase: (1) changes in general 
and brand-specific self-reported price of the most recent cigarette package purchased, (2) brand switching and other behaviours that could offset price increases and (3) changes in cigarette consumption, including quit behaviour.

\section{METHODS \\ Study sample}

Data for this study were taken from the Mexican administration of the International Tobacco Control Policy Evaluation Survey (ITC-Mexico), a population-based longitudinal survey of adult smokers designed to evaluate the behavioural and psychosocial effects of national-level policies promoted by the WHO Framework Convention on Tobacco Control (FCTC). ${ }^{14-16}$ Baseline ITC-Mexico data were collected between September and November 2006, and wave 2 follow-up data were collected between November and December 2007. Participants were randomly selected using a stratified multistage sampling design within the urban areas of four large Mexican Cities (Mexico City, Guadalajara, Tijuana and Ciudad Juarez), for which ITCMexico data are representative. Within each city, 40 block groups were selected, with selection probability proportional to the number of census tract and block-group inhabitants, according to the 2000 census. Households in selected block groups were visited in a random order, up to 4 times on different hours and days of the week, in order to enumerate households and identify eligible adult smokers (ie, 18 years or older, smoked at least once a week and had smoked at least 100 lifetime cigarettes). A maximum of one woman and one man were interviewed per household, and approximately seven interviews were conducted in each selected block group. Data were collected through face-to-face interviews taking 40 to $50 \mathrm{~min}$. At baseline, contact was established with 65\% (2787/4282) of households approached, of which $90 \%$ were enumerated, yielding a household enumeration rate of $58 \%$. Interviews were conducted with $89 \%(1079 / 1216)$ of smokers selected to participate from these enumerated households. Of the 1079 participants interviewed at baseline (ie, 263 in Mexico City, 280 in Guadalajara, 273 in Tijuana and 263 in Ciudad Juarez), ${ }^{17}$ $70.1 \% \quad(n=756)$ were followed-up in 2007. The follow-up protocol involved visiting households up to 10 times at different times and days in order to reinterview participants. Data on reasons for attrition are incomplete and unable to be analysed. The sampling weights account for the probability of household selection, with additional adjustment for the number of smokers of the same sex within the household, so that weighted population estimates are representative of the urban populations sampled.

\section{Measures}

\section{Smoking perceptions and behaviour}

Various smoking-related cognitions and behaviour were assessed. After assessing daily or non-daily smoking, daily smokers reported their average daily cigarette consumption, whereas non-daily smokers reported the average quantity they smoked each week, from which average daily consumption was derived. For some stratified analyses, the sample was divided into heavy versus light consumption using median daily consumption. Questions were also asked concerning preferred brand; the place of last purchase, with precoded response options reflecting most prevalent purchase sites (eg, convenience stores), as well as those used to avoid taxes (eg, duty free, internet); whether the last purchase was a single cigarette, a pack, or a carton of packs (ie, 10 packs of 20 cigarettes each); and the brand purchased and nominal price paid at last cigarette purchase. To derive the real price, self-reported nominal prices were adjusted for inflation using the general price index. At both waves, respondents indicated how long ago their last serious quit attempt ended, from which a variable reflecting a quit attempt in the previous year was derived. Intention to quit was also assessed (ie, in the next month; the next 6 months; after the next 6 months; or no intention to quit), which was recoded to reflect intention to quit in the next 6 months versus not, as previous work suggests this variable predicts subsequent cessation efforts. ${ }^{18}$ Smokers at both waves were also asked how much (ie, not at all; somewhat; very much) the price of cigarettes had caused them to think about quitting in the last 6 months. At follow-up, participants were asked if they had quit smoking, and those who had quit for 30 days or more were classified as quitters.

\section{Control variables}

Standard questions assessed age, sex, marital status, highest level of educational achievement, employment status and monthly household income. The seven response options for educational achievement were recoded to terciles (low=primary school or less; $\mathrm{mid}=$ secondary or technical school; high=high school or more), as were the seven options for monthly household income (low $=\$ 0$ to $\$ 3000$; $\mathrm{mid}=\$ 3001$ to $\$ 5000$; high $=$ more than $\$ 5000$ ).

\section{Analysis}

The primary analytic sample for this study consisted of smokers who were successfully followed-up over time, in order to control for unmeasured characteristics that may otherwise confound the results. The secondary analytic sample for sensitivity analyses included the entire baseline sample, including those who were and were not followed-up. Analyses were conducted with Stata V.9.2 (Stata, College Station, Texas, USA). $\chi^{2}$ Tests and independent sample $t$ tests were used to compare sociodemographic characteristics and smoking behaviour among participants who were and were not successfully followed-up, as well as to compare the baseline sample with the subsample that was followed. All other estimates and significance tests were adjusted for sampling weights and the survey design, ${ }^{19}$ including paired sample t tests to assess differences in continuous variables (eg, price, consumption) and $\chi^{2}$ tests for categorical variables (eg, consumption of single cigarettes, place of last purchase). Logistic models were estimated, regressing self-reported quit status at follow-up on baseline intensity of consumption and other explanatory variables. Sensitivity analyses of cigarette consumption changes involved estimating bivariate and multivariate random effects linear regression models, adjusting for intraindividual correlation of data from participants observed at both waves. The survey wave was included as a dummy variable to assess changes over time.

\section{RESULTS}

Table 1 presents characteristics of the entire baseline sample, as well as of the smokers who were and were not followed-up. No statistically significant differences were found between the entire baseline sample and the sample that was followed-up. However, when compared to those who were not followed-up, those who were successfully followed-up were more likely to be women, older, less educated and have a lower household income than respondents who did not participate in the second wave. No significant differences in smoking-related variables were found between those who were and were not followed-up.

Most smokers reported buying packs of cigarettes at their last purchase, but the proportion decreased at wave 2 (from $89.9 \%$ to $78.3 \% ; \mathrm{p}<0.01$ ), while the proportion of smokers who bought 
Table 1 Smoking behaviour and demographic characteristics of baseline sample, participants followed to wave 2 and participants lost to follow-up†

\begin{tabular}{|c|c|c|c|c|c|c|}
\hline \multirow[b]{2}{*}{ Characteristics at baseline (2006) } & \multicolumn{2}{|c|}{$\begin{array}{l}\text { All participants at } \\
\text { wave } 1 \\
\text { ( } n=1079)\end{array}$} & \multicolumn{2}{|c|}{$\begin{array}{l}\text { Followed-up } \\
(n=756)\end{array}$} & \multicolumn{2}{|c|}{$\begin{array}{l}\text { Not followed-up } \\
(\mathrm{n}=323)\end{array}$} \\
\hline & Mean/\% & $\mathbf{n}$ & Mean/\% & $\mathbf{n}$ & Mean/\% & $\mathbf{n}$ \\
\hline $\mathrm{Age}^{* *}$ & 39.10 & 1079 & 40.2 & 756 & 36.5 & 323 \\
\hline \multicolumn{7}{|l|}{$\operatorname{Sex}^{*}$} \\
\hline Female & $39.5 \%$ & 426 & $41.8 \%$ & 316 & $34.1 \%$ & 110 \\
\hline Male & $60.5 \%$ & 653 & $58.2 \%$ & 440 & $65.9 \%$ & 213 \\
\hline \multicolumn{7}{|l|}{ Marital status } \\
\hline Couple & $65.6 \%$ & 706 & $66.5 \%$ & 502 & $63.6 \%$ & 204 \\
\hline Separated/widowed & $12.6 \%$ & 136 & $12.6 \%$ & 95 & $12.8 \%$ & 41 \\
\hline Single & $21.7 \%$ & 234 & $20.9 \%$ & 158 & $23.7 \%$ & 76 \\
\hline \multicolumn{7}{|l|}{ Education level** } \\
\hline Primary graduate or less & $30.3 \%$ & 320 & $33.4 \%$ & 248 & $22.9 \%$ & 72 \\
\hline Secondary graduate & $37.4 \%$ & 395 & $34.6 \%$ & 257 & $43.8 \%$ & 138 \\
\hline $\begin{array}{l}\text { High school or technical school } \\
\text { graduate or more }\end{array}$ & $32.4 \%$ & 342 & $31.9 \%$ & 237 & $33.3 \%$ & 105 \\
\hline \multicolumn{7}{|l|}{ Employment status } \\
\hline Employed & $68.7 \%$ & 337 & $67.8 \%$ & 511 & $70.9 \%$ & 229 \\
\hline Unemployed or inactive $\neq$ & $31.3 \%$ & 740 & $32.2 \%$ & 243 & $29.1 \%$ & 94 \\
\hline \multicolumn{7}{|l|}{ Monthly household income* } \\
\hline Low (\$0 to $\$ 3000$ pesos) & $25.2 \%$ & 248 & $27.9 \%$ & 190 & $19.1 \%$ & 58 \\
\hline Medium ( $\$ 3001$ to $\$ 5000$ pesos) & $32.5 \%$ & 320 & $30.8 \%$ & 210 & $36.2 \%$ & 110 \\
\hline High ( $\$ 5001$ pesos or more) & $42.4 \%$ & 418 & $41.3 \%$ & 282 & $44.7 \%$ & 136 \\
\hline \multicolumn{7}{|l|}{ Smoking status } \\
\hline Daily & $77.8 \%$ & 840 & $77.9 \%$ & 589 & $77.7 \%$ & 251 \\
\hline Less than daily & $22.2 \%$ & 239 & $22.1 \%$ & 167 & $22.3 \%$ & 72 \\
\hline No. of cigarettes per day & & 1052 & 8.1 & 739 & 7.9 & 313 \\
\hline \multicolumn{7}{|l|}{ Form of last cigarette purchase } \\
\hline Pack of cigarettes & $90.5 \%$ & 963 & $90.4 \%$ & 671 & $90.7 \%$ & 292 \\
\hline Single cigarette & $9.1 \%$ & 97 & $9.3 \%$ & 69 & $8.7 \%$ & 28 \\
\hline Carton of 10 cigarette packs & $0.4 \%$ & 4 & $0.3 \%$ & 2 & $0.6 \%$ & 2 \\
\hline $\begin{array}{l}\text { Self-reported price of last pack purchased } \\
\text { (MX\$ November 2007) }\end{array}$ & $\$ 20.83$ & 957 & $\$ 20.76$ & 666 & $\$ 21.00$ & 291 \\
\hline \multicolumn{7}{|l|}{ Made serious quit attempt in previous year } \\
\hline Yes & $25.8 \%$ & 278 & $26.5 \%$ & 200 & $24.2 \%$ & 78 \\
\hline No & $74.2 \%$ & 801 & $73.5 \%$ & 556 & $75.9 \%$ & 245 \\
\hline \multicolumn{7}{|l|}{ Plan to quit } \\
\hline Within the next month/next 6 months & $17.0 \%$ & 171 & $17.3 \%$ & 122 & $16.4 \%$ & 49 \\
\hline Beyond 6 months/not planning to quit & $83.0 \%$ & 833 & $82.7 \%$ & 584 & $83.6 \%$ & 249 \\
\hline
\end{tabular}

single cigarettes followed the opposite pattern (from $9.9 \%$ to $20.2 \%: \mathrm{p}<0.01$ ). The average price per cigarette increased (from 1.9 to 2.4 pesos; $p<0.015$ ), with a higher price per cigarette than when sticks were purchased in packs (1.0-1.1 pesos). Only two smokers bought cartons of cigarettes in both waves, so the price per cigarette was not estimated.

Table 2 shows the self-reported price of last cigarette pack purchased at waves 1 and 2, including only those whose last purchase was a pack in both surveys. An overall price increase of $12.7 \%$ was found $(p<0.01)$. When analysing price for those who purchased an international brand at both waves independent of the type of international brand, the price increase was higher than for those who bought national brands at both waves $(13.5 \%$ vs $8.7 \%$, respectively; $\mathrm{p}<0.01)$. In Mexico, international and national brands are rough equivalents of premium and discount brands, as indicated by significant different price across types. Brand-specific estimates were calculated only for people who bought that brand at both waves. At wave 2, no international brand was cheaper than any national brand. Table 2 shows the brand-specific prices for the most prevalent brands purchased in our sample; statistically significant increases in price were found across all brands but two, which had small sample sizes.

A quarter of the smokers who continued smoking switched their preferred brand $(n=158)$. No clear switching pattern was found, however. Of those who switched, approximately a quarter switched from a national to a more expensive international brand $(\mathrm{n}=41)$, a quarter switched from an international to a less expensive national brand $(n=41)$, whereas the rest switched within national or international brand categories ( $\mathrm{n}=24$ and 52, respectively).

In both waves, nearly $95 \%$ of last cigarette purchases were made in local or convenience stores (from 79.3\% to $83.8 \%$ ), $24 \mathrm{~h}$ convenience stores (from $11.2 \%$ to $6.6 \%$ ) or supermarkets (from $3.5 \%$ to $3.3 \%$ ), none of which changed significantly over time. Sources that could offset price increases were used infrequently (ie, duty free shops from $3.3 \%$ to $0.4 \%$; purchase outside the country from $0.1 \%$ to $0.1 \%$ ) or not at all (ie, internet $0 \%$ to $0 \%$ ). 
Table 2 Average self-reported cigarette pack price among smokers whose last purchase was a pack at both survey waves (MX\$ November 2007)‡

\begin{tabular}{lllcr}
\hline & Baseline & Follow-up & $\begin{array}{c}\text { Percentage } \\
\text { change }\end{array}$ & n \\
\hline All brands in the sample & $\$ 20.15$ & $\$ 22.70$ & $12.7 \%^{* *}$ & 490 \\
All national brands in the sample $\dagger$ & $\$ 17.52$ & $\$ 19.04$ & $8.7 \%^{* *}$ & 107 \\
$\quad$ Montana & $\$ 18.43$ & $\$ 20.40$ & $10.7 \%^{* *}$ & 30 \\
Raleigh & $\$ 20.00$ & $\$ 21.41$ & $7.1 \%^{* *}$ & 22 \\
Boots & $\$ 16.68$ & $\$ 19.71$ & $18.2 \%^{*}$ & 14 \\
$\quad$ Delicados & $\$ 13.60$ & $\$ 16.19$ & $19.0 \%^{*}$ & 16 \\
All international brands in the sample§ $\$ 21.05$ & $\$ 23.89$ & $13.5 \%^{* *}$ & 320 \\
$\quad$ Marlboro & $\$ 21.29$ & $\$ 23.97$ & $12.6 \%^{* *}$ & 239 \\
Camel & $\$ 19.50$ & $\$ 23.37$ & $19.8 \%^{* *}$ & 17 \\
Benson & $\$ 22.50$ & $\$ 24.13$ & $7.2 \%$ & 23 \\
\hline
\end{tabular}

${ }^{*} \mathrm{p}<0.05 ;{ }^{* *} \mathrm{p}<0.01$.

tOther national brands (ie, Broadway, Faros and Fiesta) purchased by less than $2 \%$ of respondents.

‡Survey-adjusted means shown for respondents who purchased cigarette packs at both waves. Exchange rate for MX\$ (Mexican peso):US\$ approximately 11:1 at both assessments. International and national estimates assessed among respondents whose last cigarette pack purchase was of the same type at both waves, although the specific brand within each category could vary. Brand-specific estimates were assessed only among those who purchased the same brand at both waves.

§Other international brands (ie, Lucky Strike, Pall Mall, Salem) purchased by less than 2\% of the respondents.

Survey adjusted average daily cigarette consumption decreased significantly from 6.9 to 4.9 cigarettes/day $(p<0.01)$ when including no consumption for participants who reported having quit at follow-up (see table 3). This overall reduction remained statistically significant when removing quitters from the analysis ( 7.2 to 5.7 cigarettes/day; $p<0.01$ ). A statistically significant decrease in consumption was found across all sociodemographic subgroups, as well as among those who did and did not intend to or try to quit in the previous year. The only evidence for differential effects over time involved baseline consumption intensity. Among heavy smokers (ie, at or above the median of five cigarettes/day), consumption declined by $39.3 \%(p<0.01)$, a decrease that was maintained when excluding those who quit smoking at follow-up. However, light smokers (ie, less than five cigarettes/day) generally maintained their consumption level over time, with a statistically significant increase found when excluding those who had quit. In sensitivity analyses that included the entire baseline and follow-up samples, consumption was regressed on time (ie, baseline vs follow-up) and other study variables. Results indicated that time was inversely associated with consumption, and planning to quit was the only other statistically significant predictor of consumption in multivariate models (results not shown). Tests of interaction between time and other variables indicated no statistically significant interactions.

A total of 98 baseline smokers (13.1\%; 95\% CI 9.7\%,16.5\%) reported being quit for at least 30 days at follow-up. Bivariate and multivariate logistic regression models were estimated to determine predictors of being quit (see table 4). The greater likelihood of quitting among light versus heavy daily consumption was the only statistically significant predictor in either bivariate $\left(R R_{\text {light vs heavy }}=2.32\right)$ or the model that adjusted for sociodemographics, quit intentions and quit behaviour $\left(A R R_{\text {light vs heavy }}=2.66\right)$. When excluding from both waves all those who were quit at wave 2 , the proportion of smokers who reported making serious quit attempts in the previous year increased from $26.1 \%$ at wave 1 to $34.5 \%$ at wave $2(\mathrm{p}<0.001)$. In addition, the price of cigarettes increased its relevance as a reason to consider quitting for those who were still smoking after the tax increase (very much: from $5.9 \%$ to $14.7 \%$;
Table 3 Average number of cigarettes smoked per day at baseline and follow-up, by baseline sociodemographic characteristics and smokingrelated variables

\begin{tabular}{|c|c|c|c|c|}
\hline & Baseline & Follow-up & $\begin{array}{l}\text { Percentage } \\
\text { change }\end{array}$ & $\mathbf{n}$ \\
\hline \multicolumn{5}{|l|}{ Cohort respondents at waves 1 and $2 \dagger$} \\
\hline Total & 6.9 & 4.9 & $-29.8 \% * *$ & 728 \\
\hline \multicolumn{5}{|l|}{ Age } \\
\hline $18-24$ & 6.2 & 4.2 & $-32.6 \% *$ & 76 \\
\hline $25-39$ & 6.0 & 4.3 & $-28.1 \% * *$ & 280 \\
\hline $40-54$ & 7.7 & 5.2 & $-31.5 \% *$ & 245 \\
\hline $55+$ & 9.1 & 6.6 & $-27.2 \% *$ & 127 \\
\hline \multicolumn{5}{|l|}{ Sex } \\
\hline Female & 6.7 & 4.4 & $-33.4 \% * *$ & 302 \\
\hline Male & 7.1 & 5.2 & $-27.6 \% * *$ & 426 \\
\hline \multicolumn{5}{|l|}{ Marital status } \\
\hline Couple & 7.0 & 5.0 & $-28.8 \% * *$ & 487 \\
\hline Separated/widowed & 8.1 & 5.3 & $-35.2 \% * *$ & 90 \\
\hline Single & 6.2 & 4.4 & $-29.2 \% * *$ & 150 \\
\hline \multicolumn{5}{|l|}{ Education level } \\
\hline Primary graduate or less & 8.2 & 5.8 & $-29.2 \% * *$ & 242 \\
\hline Secondary graduate & 6.2 & 4.5 & $-27.2 \% * *$ & 247 \\
\hline High school graduate or more & 6.7 & 4.5 & $-33.3 \% * *$ & 225 \\
\hline \multicolumn{5}{|l|}{ Employment status } \\
\hline Employed & 7.1 & 5.1 & $-27.0 \% * *$ & 489 \\
\hline Unemployed or inactive $\neq$ & 6.7 & 4.3 & $-35.5 \% * *$ & 237 \\
\hline \multicolumn{5}{|l|}{ Monthly household income } \\
\hline Low ( $\$ 0$ to $\$ 3000$ pesos) & 6.4 & 4.7 & $-26.9 \% * *$ & 185 \\
\hline Medium ( $\$ 3001$ to $\$ 5000$ pesos) & 6.2 & 4.1 & $-34.6 \% * *$ & 205 \\
\hline High ( $\$ 5001$ pesos or more) & 8.0 & 5.9 & $-26.8 \% * *$ & 267 \\
\hline \multicolumn{5}{|l|}{ Smoking status§ } \\
\hline Heavy smoker & 12.3 & 7.4 & $-39.3 \% * *$ & 372 \\
\hline Light smoker & 2.8 & 2.9 & $2.1 \%$ & 356 \\
\hline \multicolumn{5}{|c|}{ Made serious quit attempt in the previous year } \\
\hline Yes & 7.0 & 4.5 & $-36.2 \% * *$ & 192 \\
\hline No & 6.9 & 5.0 & $-27.3 \% * *$ & 536 \\
\hline \multicolumn{5}{|l|}{ Plan to quit } \\
\hline Within the next month/next 6 months & 5.7 & 4.0 & $-30.7 \% * *$ & 118 \\
\hline Beyond 6 months/not planning to quit & 7.2 & 5.0 & $-30.1 \% * *$ & 561 \\
\hline \multicolumn{5}{|c|}{ Only cohort respondents who continued smoking at wave $2 \Phi$} \\
\hline Total & 7.2 & 5.7 & $-20.7 \% * *$ & 635 \\
\hline \multicolumn{5}{|l|}{ Smoking status } \\
\hline Heavy smoker & 12.2 & 8.2 & $-33.0 \% * *$ & 336 \\
\hline Light smoker & 2.9 & 3.6 & $24.8 \% *$ & 299 \\
\hline
\end{tabular}

t Tests: ${ }^{*} \mathrm{p}<0.05,{ }^{* *} \mathrm{p}<0.01$.

† Survey-adjusted averages include 0 consumption for those who quit smoking at wave 2 (data only for the 728 of those followed-up who reported consumption at both waves; of whom 93 reported having been quit for at least a month before wave 2).

†Inactive means retired or on a pension, student, or home duties.

§Heavy smoker: consumption above the median of five cigarettes per day at wave 1 .

- Survey-adjusted averages exclude those who had quit smoking at wave 2.

somewhat: from $19.4 \%$ to $35.3 \%$; $<<0.01)$. Among smokers who had quit by follow-up $(n=98), 40.1 \%$ reported that the price of cigarettes was either a very important $(12.7 \%)$ or a somewhat important $(27.4 \%)$ reason for quitting. Nevertheless, other selfreported reasons for quitting appeared more relevant than price, such as one's family being concerned about their health $(75.8 \%=$ very much) and health reasons $(60.0 \%=$ very much).

\section{DISCUSSION}

This study adds to the evidence base on how tax increases are passed on to consumers, which rarely has been studied in lowincome and middle-income countries. Results indicated that the average self-reported real price for cigarettes, which is a valid estimate of price ${ }^{20}$ increased by $12.7 \%$ from 2006 to 2007 . Given the characteristics of how taxes are applied in Mexico, ${ }^{13}$ a price 
Table 4 Percentage and relative risk (RR) of quitting at follow-up

\begin{tabular}{|c|c|c|c|c|}
\hline $\begin{array}{l}\text { Sociodemographics and smoking- } \\
\text { related variables }\end{array}$ & Percentage quit & (n) & Crude RR (95\% Cl) & Adjusted RR $\neq(95 \%$ Cl) \\
\hline Age & & $(-756)$ & $1(0.99$ to 1.02$)$ & $1.02(1.00$ to 1.04$)$ \\
\hline \multicolumn{5}{|l|}{ Sex } \\
\hline Male & $12.20 \%$ & $(-440)$ & 1 & 1 \\
\hline Female & $14.60 \%$ & $(-316)$ & $1.23(0.69$ to 2.21$)$ & $1.01(0.45$ to 2.24$)$ \\
\hline \multicolumn{5}{|l|}{ Marital status } \\
\hline Couple & $12.60 \%$ & $(-502)$ & 1 & 1 \\
\hline Separated/widowed & $9.20 \%$ & $(-95)$ & $0.7(0.34$ to 1.45$)$ & $0.8(0.29$ to 2.15$)$ \\
\hline Single & $16.70 \%$ & $(-158)$ & $1.39(0.59$ to 3.28$)$ & $1.64(0.67$ to 4.04$)$ \\
\hline \multicolumn{5}{|l|}{ Education } \\
\hline Primary graduate or less & $11.50 \%$ & $(-248)$ & 1 & 1 \\
\hline Secondary graduate & $13.40 \%$ & $(-257)$ & $1.19(0.52$ to 2.72$)$ & $1.29(0.52$ to 3.23$)$ \\
\hline High school graduate or more & $15.20 \%$ & $(-237)$ & $1.38(0.69$ to 2.75$)$ & $1.5(0.60$ to 3.75$)$ \\
\hline \multicolumn{5}{|l|}{ Employment status } \\
\hline Unemployed or inactive & $16.20 \%$ & $(-243)$ & 1 & 1 \\
\hline Employed & $11.80 \%$ & $(-511)$ & $0.69(0.33$ to 1.47$)$ & $0.6(0.24$ to 1.52$)$ \\
\hline \multicolumn{5}{|l|}{ Income } \\
\hline Low ( $\$ 0$ to $\$ 3000$ pesos) & $15.20 \%$ & $(-190)$ & 1 & 1 \\
\hline Medium ( $\$ 3001$ to $\$ 5000$ pesos) & $13.60 \%$ & $(-210)$ & $0.88(0.37$ to 2.07$)$ & $1.03(0.48$ to 2.22$)$ \\
\hline High ( $\$ 5001$ pesos or more) & $9.80 \%$ & $(-282)$ & $0.61(0.22$ to 1.63$)$ & $0.55(0.20$ to 1.51$)$ \\
\hline \multicolumn{5}{|l|}{ Smoking status } \\
\hline Heavy smoker & $9.50 \%$ & $(-378)$ & 1 & 1 \\
\hline Light smoker $†$ & $15.80 \%$ & $(-361)$ & $2.32^{*}(1.34$ to 4.03$)$ & $2.66^{*}(1.41$ to 4.99$)$ \\
\hline \multicolumn{5}{|c|}{ Made serious quit attempts the previous year } \\
\hline No & $13.10 \%$ & $(-556)$ & 1 & 1 \\
\hline Yes & $13.10 \%$ & $(-200)$ & $1(0.53$ to 1.92$)$ & $0.9(0.45$ to 1.78$)$ \\
\hline \multicolumn{5}{|l|}{ Plan to quit within the next 6 months } \\
\hline No & $11.90 \%$ & $(-584)$ & 1 & 1 \\
\hline Yes & $16.50 \%$ & $(-122)$ & $1.46(0.71$ to 3.03$)$ & 1.31 (0.63 to 2.72$)$ \\
\hline Observations & & & & 621 \\
\hline
\end{tabular}

increase of $14.3 \%$ was hypothesised. Hence, the overall price increase was lower than expected, but less so for international brands $(13.5 \%)$. The lower relative price increase for national brands $(8.7 \%)$ suggests that the full tax was not passed onto consumers of these cheaper brands. This strategy likely aims to reduce the impact of the tax increase by keeping some brands cheap, including the possibility of encouraging switching to a cheaper brand instead of quitting. How taxes are passed onto consumers may reflect any number of factors, including the structure of the industry and how retailer markups are applied. Future research should assess the relative influence of these factors, which could not be analysed with data reported here.

Our results also suggest a general absence of efforts by smokers to offset the price increase of cigarettes. Study participants who switched brands switched to higher-priced brands as often as they switched to lower-priced brands; however, the small sample size of people who switched brands precluded a more detailed analysis of this behaviour. In general, however, Mexican cigarette smokers appeared generally loyal to their brands and appeared to have reduced consumption or quit instead of switching to a cheaper brand. ${ }^{21}$ Furthermore, the vast majority of smokers $(95 \%)$ continued to purchase cigarettes at stores and supermarkets, with no increase in the prevalence of purchasing from sites that could sell cheaper cigarettes (eg, internet, duty free shops, outside the country). This may reflect the relative inaccessibility of outlets for cheaper cigarettes in Mexico. For example, access to duty free shops and the internet is still limited, and tobacco taxes are levied only at the federal level, so Mexican smokers generally do not have ready access to nearby lower tax jurisdictions. Smuggling of cheaper contraband cigarettes could diminish the impact of tax increases on consumption. However, contraband in Mexico seems relatively low. In 2006, for example, contraband sales were estimated at $3.3 \%$ of total cigarette sales, ${ }^{22}$ compared to a global average of $11 \%{ }^{23}$ This may be due to generally higher cigarette prices for cigarettes from the US (Mexico's primary neighbour), as higher prices are likely to impede the flow of contraband. Future analysis should investigate these issues in greater detail.

Another important finding concerns the 29\% decrease in consumption after the tax increase, a decrease that was relatively consistent across groups defined by sociodemographics and readiness to quit. According to previous estimates of price elasticity in Mexico, ${ }^{7}$ a $12.3 \%$ increase in prices would be expected to reduce consumption by $6.4 \%$, far less than the reduction observed. Our results may overestimate the impact of the tax increase if selfreported consumption reflects short-term cessation and reduction efforts that are unsuccessful in the long run. Greater than expected reductions in consumption may also be accounted for by selection bias, survey participation serving as an intervention, an increase in socially desirable responding in the second wave, or secular trends. Indeed, debates over local and federal tobacco control policy increased markedly toward the end of $2007,{ }^{24}$ when data for the present study were collected. Data collected in 2008, after smokefree legislation came into force, indicate significant increases in perceived unacceptability of smoking, mostly in Mexico City ${ }^{21} 25$ but also in other regions of the country. ${ }^{26}$

Our results suggest that relative declines in consumption were greatest among heavier smokers and non-existent among 
smokers with a lighter habit. This finding reflects general economic theory about greater relative declines in consumption among people who consume more of the product. ${ }^{3}$ Nevertheless, lighter smokers were more likely than heavier smokers to quit over the observation period, which is a more desirable public health outcome than reduced consumption. Furthermore, prevalence of single cigarette consumption increased over this time, which other studies have indicated that Mexican smokers use as a quitting strategy, since single cigarettes cost more and it requires extra effort to obtain each cigarette, as opposed to the easy access that a pack provides. ${ }^{27}$

A limitation of this analysis concerns the inability to attribute the observed decreases in consumption directly to the tax increase. Since the cigarette tax was implemented at the national level, there is no unexposed control group with which to compare changes found. Furthermore, since this is the first longitudinal study of a population-based representative sample of Mexico smokers, we cannot compare cessation rates in our sample with those that have occurred over a similar time period in the absence of a tax increase. Increases in media coverage of proposed tobacco control legislation could help account for our findings, however, no media campaigns or other tobacco control policies were implemented in 2007, at either the national level or within the cities considered. Indeed, key predictors of cessation (ie, past year quit behaviour, intention to quit) did not predict being quit for 30 days in our sample, suggesting that some other variable accounts for observed changes. Given the great consistency of tax impacts, it appears that at least some of the observed changes in consumption can be attributed to the tax increase.

The panel design we used strengthened our study's internal validity, although a number of factors may have compromised the generalisability of the results. Our data were from a population-based, representative sample of smokers from four of the largest cities in Mexico, but these smokers may differ from smokers in other cities and in rural areas. The baseline average daily consumption of cigarettes by smokers in our sample (6.9 cigarettes/day) was nevertheless comparable to consumption reported in the 2002 National Survey on Addiction (6.4 cigarettes/day). ${ }^{28}$ The enumeration of households selected from within our sampling frame was lower than desired (58\%), which may have introduced selection bias even though participation was high (89\%) among smokers identified from enumerated households. We did not collect data on households or people who did not participate in the study; hence, the directionality of this potential bias could not be assessed. Nevertheless, the socioeconomic characteristics of our sample are consistent with those from the 2008 Mexican National Household Income and Expenses Survey, providing some evidence for the external validity for the results. Furthermore, no statistically significant differences were found between the baseline sample and the subsample that was successfully followed-up, even though the attrition rate was higher than desired (30\%), and participants who were and were not followed-up differed in terms of some sociodemographic characteristics. The somewhat lower income among those who were followed-up may have resulted in a primary analytic sample that was more price sensitive than the entire baseline sample. However, within the primary analytic sample, decreases in consumption were consistent across income levels, and no differences were found between the two samples with regard to smoking-related variables, which suggests that attrition bias may be minimal. Finally, sensitivity analyses that included all baseline observations produced results that were consistent with those reported in detail. Although a number of

\section{What this paper adds}

- Numerous studies have shown that taxes are an effective policy tool to reduce tobacco consumption. In Mexico, smokers appear price sensitive, but research on this question has used aggregate or household-level consumption data and, as such, has not been able to assess the impact of taxes on individual perceptions and behaviour. In most cases, studies based on individual-level data have been conducted in highincome countries.

- Individual-level responses to significant tax increases have rarely been examined among smokers in low-income or middle-income countries. This study indicates that the tax increase implemented in Mexico in 2007 was generally passed onto consumers, but with greater increases in price for international brands than national brands.

- No clear evidence was found for efforts to offset the price increase. Consistent declines in consumption across groups defined by sociodemographic and smoking-related psychosocial variables suggest a relatively uniform impact of the tax increase across subpopulations of Mexican smokers.

factors may have compromised the external validity of the study results, there is some evidence to suggest that the results are somewhat generalisable.

\section{Conclusions}

This study expands the evidence around the impact of tax increases in low-income or middle-income countries. Results indicate that the tax increase implemented in January 2007 effectively increased the prices that Mexican smokers paid for cigarettes and that average consumption decreased concurrently across sociodemographic groups. The decrease in consumption was higher than price elasticity estimates would predict. Although the lack of an overall reduction among lighter smokers is suggestive of a differential impact, these smokers were more likely than heavy smokers to have quit at follow-up. Future research should aim to rule out potential biases that may account for these results. However, this study was the first population-based, longitudinal study of tax impacts among adult smokers in Mexico, and results support the emphasis on tax policy within the WHO FCTC.

Acknowledgements Funding for data collection on this study came from the University of Illinois at Chicago, Cancer Center, Cancer Education and Career Development Program (RA25-CA57699), and the Roswell Park Transdisciplinary Tobacco Use Research Center (TTURC-P50 CA111236), both of which were funded by the US National Cancer Institute, and the Union Against Tuberculosis and Lung Disease (Mexico 1-06). Analysis and writing of the article was funded by the Mexican National Council on Science and Technology (Convocatoria Salud-2007C01-70032), with additional funding provided by the Ontario Institute for Cancer Research and an unrestricted grant from Johnson \& Johnson.

Funding Consejo Nacional de Ciencia y Tecnología, México. National Institutes of Health.

\section{Competing interests None.}

Ethics approval This study was conducted with the approval of the Instituto Nacional de Salud Pública, México and the University of Illinois, Chicago, USA.

Provenance and peer review Not commissioned; externally peer reviewed.

\section{REFERENCES}

1. WHO. WHO report on the global tobacco epidemic, 2008: The MPOWER package Geneva: World Health Organization, 2008. 
2. Chaloupka FJ, Hu TW, Warner KE, et al. The taxation of tobacco products. In: Chaloupka FJ, Jha P, eds. Tobacco control in developing countries. Oxford: Oxford University Press, 2000:237-72.

3. Chaloupka FJ, Warner KE. The economics of smoking. In: Cuyler AJ, Newhouse JP, eds. Handbook of economics. Amsterdam: Elsiever, 2000.

4. Jha P, Chaloupka FJ. Curbing the epidemic: Governments and the economics of tobacco control. Washington, DC: The International Bank for Reconstruction and Development, 1999.

5. Sesma-Vásquez S, Campuzano JC, Carreón-Rodríguez VG, et al. El comportamiento de la demanda de tabaco en México. Revista de Salud Pública de México 2002;44 (Supp I):S82-92.

6. Sesma-Vásquez S, Pérez-Rico R, Puentes-Rosas E, et al. El precio como determinante como consumo de tabaco en México, 1994-2002. In: Valdés Salgado R, Lazcano-Ponce EC, Hernández-Avila M, eds. Cuernavaca, Morelos: Instituto Nacional de Salud Pública. 2005:125-32.

7. Jiménez JA, Sáenz de Miera B, Reynales-Shigematsu LM, et al. The impact of fiscal policy on tobacco consumption in Mexico. Tob Control 2008;17(1):105-10.

8. Chaloupka FJ. Tobacco control lessons learned: The impact of state and local policies. ImpacTeen Research Paper Number 38. Chicago: Health Policy Center, University of Illinois at Chicago.

9. Chaloupka FJ, Cummings KM, Morley CP, et al. Tax, price and cigarette smoking: evidence from the tobacco documents and implications for tobacco company marketing strategies. Tob Control 2002;11(Supp 1):i62-72.

10. Hyland A, Bauer J, Li 0 , et al. Higher cigarette prices influence cigarette purchase patterns. Tob Control 2005;14:86-92.

11. Hyland A, Laux F, Higbee C, et al. Cigarette purchase patterns in four countries and its relationship with cessation: findings from the International Tobacco Control Policy Evaluation Survey. Tob Control 2006:15(Supp 3):iii59-64.

12. Tsai $\mathbf{Y}$, Chung-Lin $Y$, Chin-Shyan $C$, et al. The effect of Taiwan's tax-induced increases in cigarette prices on brand-switching and the consumption of cigarettes. Health Econ 2005; 14:627-41.

13. Waters H, Saenz de Miera B, Ross H, Reynales-Shigematsu LM. The Economics of Tobacco and Tobacco Taxation in Mexico. Paris: International Union against Tuberculosis and Lung Disease, 2010. ISBN: 978-2-914365-73-4.

14. WHO. Framework Convention on Tobacco Control. Geneva, Switzerland: World Health Organization, Tobacco Free Initiative, 2003.

15. Thrasher JF, Chaloupka FJ, Hammond D, et al. Evaluación de las políticas contra el tabaquismo en países latinoamericanos en la era del Convenio Marco para el Control del Tabaco [Evaluation of tobacco control policies in Latin American countries during the era of the Framework Convention on Tobacco Controll. Salud Pública de México 2006;48(Supp 1):S155-66.

16. Fong GT, Cummings KM, Borland $\mathrm{R}$, et al. The conceptual framework of the International Tobacco Control Policy Evaluation Project. Tob Control 2006;15(Supp 3): iii3-11.

17. Thrasher JF, Boado M, Sebrié EM, et al. Smoke-free policies and the socia acceptability of smoking in Uruguay and Mexico: findings from the Internationa Tobacco Control Policy Evaluation (ITC) Project. Nicotine Tob Res 2009;11:591-9.

18. Hyland A, Borland R, Li Q, et al. Individual-level predictors of cessation behaviours among participants in the International Tobacco Control (ITC) Four Country Survey. Tob Control 2006;15(Supp 3):iii83-94.

19. StataCorp. Survey data reference. Austin, TX: STATA Press, 2005

20. Hartman AM, Chaloupka FJ, Tauras JA, et al. What is the real price of cigarettes? Society for Research on Nicotine and Tobacco. Dublin, Ireland, 2009.

21. Thrasher JF, Besley JC, González W. Perceived justice and popular support for public health laws: a case study around comprehensive smoke-free legislation in Mexico City. Soc Sci Med 2010:70:787-93.

22. ERC Group. World Cigarettes 1. The 2007 Survey: Americas. Suffolk, UK: ERC Group Ltd, 2007.

23. Shafey 0, Eriksen M, Ross $\mathrm{H}$, et al. The tobacco atlas. Atlanta, GA: The American Cancer Society, 2009

24. Llaguno-Aguilar SE, Dorantes-Alonso AC, Thrasher JF, et al. Análisis de la cobertura del tema de tabaco en medios impresos mexicanos [Analysis of the coverage of tobacco in Mexican print media]. Salud Pública de México 2008;50 (Supp 3):S348-54

25. Thrasher JF, Pérez-Hernández R, Swayampakala K, et al. Policy support, norms, and secondhand smoke exposure before and after implementation of a comprehensive smoke-free policy in Mexico City. Am J Public Health 2010;100:1789-98.

26. Thrasher JF, Swayampakala K, Villalobos V, et al. Differential impact of local and federal smoke-free legislation in Mexico: a longitudinal study among adult smokers. Salud Pública de México. In press.

27. Thrasher JF, Villalobos V, Dorantes-Alonso A, et al. Does the availability of single cigarettes promote or inhibit cigarette consumption?: Perceptions, prevalence and correlates of single cigarette use among adult Mexican smokers. Tob Control 2009;18:431-7.

28. Franco-Marina F. Adult smoking trends in Mexico: an analysis of the Mexican Nationa Addiction Survey. Salud Pública de México 2007:49(Supp 2):S137-46. 